Article

\title{
The Role of Perceived Social Support in the Psychological Well-Being of Young Offenders: from Pretrial Detention to Correctional Camps
}

\author{
Fedor Ushkov ${ }^{1}$, Roman Shilko ${ }^{1, *}$, Ludmila Shaigerova ${ }^{1}$, Alexandra Dolgikh ${ }^{1}$, Olga Almazova ${ }^{1}$, \\ Olga Vakhantseva ${ }^{1}$ and Yuri Zinchenko ${ }^{1}$ \\ 1 Lomonosov Moscow State University, Faculty of Psychology; Mokhovaya Str., 11, Bld. 9, Moscow, 125009, \\ Russia; psy@psy.msu.ru \\ * Correspondence: shilko_rs@psy.msu.ru; Tel.: +7-495-629-3723
}

\begin{abstract}
The present article aims at investigating the role of social support in the emotional well-being of young offenders. We hypothesized that perceived social support would be positively related to the emotional well-being of juvenile offenders. The methods were worked out to study perceived and received social support, psychological well-being and emotional state of the juvenile offenders. The entire sample consisted of 56 males aged from 15 to 18 years old ( $M=16.5 ; S D=0.8$ ). 32 subjects $(57 \%)$ were in pretrial detention and 24 participants $(43 \%)$ were in a correctional camp located in the central region of Russia. The study detected that the level of psychological well-being of the respondents from the camp was correlated neither with perceived social support nor with the frequency of seeking assistance from the different sources of support. For the respondents in the pretrial detention, the level of psychological well-being was directly connected to the degree of the perceived support from the friends. The obtained differences might be associated with the influence of social environment in the pretrial detention and in the camps.
\end{abstract}

Keywords: psychological well-being; young offenders; social support; pretrial detention; correctional camps; positive and negative feelings; positive and negative affects

\section{Introduction}

\subsection{Psychological Well-being and Emotional State in Adolescence}

The problem of mental health and psychological well-being of the growing generation is among the most important issues of modern society. The deterioration of mental health of young adults in recent decades is an objective reality: the research in both Western and Eastern societies indicates that mental disorders among the younger generation are more frequent than in the population on average [1,2]. According to the World Health Organization, depression is one of the leading causes of disease and disability among adolescents. And the consequences of not addressing adolescent mental health problems extend to adulthood, impairing both physical and mental health and limiting opportunities to lead fulfilling lives as adults [3].

Special attention should be paid to the mental health and psychological well-being of juvenile offenders. The prevalence of undiagnosed mental disorders and the disadvantaged social situation of development often overlap with the particularities of adolescence and become a trigger for illegal actions leading to committing crimes of varying severity. In addition, studies in different countries indicate that recidivism and its severity are very high in serious juvenile offenders [4-6]. The high level of recidivism in adolescent perpetrators is widespread regardless of the criminal justice system, the severity of the sentencing against minors and the corrective measures employed [7]. In some countries, the rate of recidivism among juvenile offenders exceeds $60 \%[5,8,9]$. Thus, juvenile offenders may be considered as a "double-risk" group: having served their sentences and been 
released from prison, most of them represent again a threat to themselves as well as to other people and society as a whole.

The need to apply a systematic approach to the study of adolescents with behavioural deviations becomes increasingly obvious. This requires taking into account various aspects: ideas about themselves, parents and other people, actual social environment and the degree of their social support and the individual's readiness to establish new relationships [10].

The study of the role of various factors determining mental health, psychological well-being and emotional state in juvenile offenders can contribute to the efficiency of correctional measures in young offenders institutions and the successful re-socialization after release. Special attention should be paid to the study of the emotional state of juvenile offenders, which is a crucial component of the psychological well-being of the individual and an indicator of mental and physical health, along with the positive functioning (independence, personal growth and so on) [11-14]. It is widely accepted to consider emotional well-being as a ratio of positive (joy, delight, attachment and happiness) and negative (guilt, shame, anger and depression) emotions and states, the so-called hedonistic balance [15] or the balance of affect.

At the same time, the emotional state of a juvenile is closely associated with the key characteristics of age: the social situation of development representing the child's place in the system of social interactions, the leading activity of the child and the new psychological structures of personality $[16,17]$. Family situation and relationships with peers are two important social spheres that affect the emotional state and psychological well-being of a teenager. The studies of the emotional state of high school students in Russia and other countries detected that, primarily, a considerable deterioration in relations with parents affects the emotional state of adolescents [18]. At the same time, the distinctive features of adolescence are the fall of the authority of the adult as the only carrier of norms and rules and the desire of minors to find their place among peers $[16,19]$. The absence of a positive assessment by the significant social environment (especially parents and peers) can lead to social maladaptation and offenses and asocial forms of behaviour.

Mental health, psychological well-being and the emotional state of adolescents awaiting court decision or serving the sentence are mediated by additional factors, such as social isolation, the lack of the possibility of independent decision-making, difficulties in adapting to the conditions of detention and the necessity to comply with formal and informal rules in the place of detention [20-22].

\subsection{Social Support as a Factor of Psychological Well-being and Emotional State}

Social support is an important factor in mental health and emotional well-being. A number of studies have shown that social support correlates with health maintenance [23], well-being [24], life satisfaction [25] positive and negative mood [26], mental stability and clarity [27] and better mental health outcomes [28]. Many researchers suggest that social support creates a buffer against effects of stressful and traumatic events $[29,30]$ and produces higher levels of self-control and environmental stability [31].

As a result of the almost half-century investigations of social support in various disciplines and fields, there is no doubt that there is a strong link between social support and psychological well-being. Nevertheless, research in this field remains relevant due to the need to search for and clarify the role of various factors in that link, in particular, the forms and sources of social support.

\subsection{Forms of Social Support}

The theoretical analysis and empirical research enable us to single out different types of social support. The most important dichotomy is the differentiation and division of social support into perceived social support and received social support [32,33]. Perceived social support refers to the perceived accessibility of social connections; received social support concentrates on the quantity and quality of the support provided. It is noteworthy that these two types of support are only marginally correlated [34,35]. Moreover, it is indicated that perceived support has a wholesome 
effect on mental health and emotional state, while the relationship between received social support and mental health and well-being is not reliably confirmed [34-36]. Sometimes, higher levels of received support are even associated with more negative mental health indicators [37,38].

\subsection{Sources of Social Support}

An individual receives social support from different social resources. Social resources are defined as an interpersonal network including family, friends, workplace from which the individual acquires a crucial support [39]. Previous studies have shown that psychological well-being, emotional state and emotional experiences are correlated with social support from different sources (family, friends and other people) in various ways [25,40]. Many researchers focus on comparing different sources of support, since the particular group or person providing social support can play a decisive role in the psychological well-being or emotional state of the subject receiving support, depending on different circumstances. The main issue of the research about the role of sources of support is whose support and in what context has a beneficial effect on the psychological well-being and emotional state of the individual [41].

Thoits divides all the social connections of the individual into two groups: a primary group and a secondary group [42]. The first group includes those people who are in a more personal relationship with the individual (family, friends and relatives). The second group includes those who are in a more formal and a less personal relationship (colleagues, neighbours and acquaintances). Despite the different degree of intimacy with the members of the two groups, social support from both groups can benefit the individual. It is proposed that the effects of different sources of social support on well-being can be examined independently, as each type of relationship may exhibit distinct influences on critical outcomes [25].

\subsection{The Role of Social Support and Social Interaction in the Psychological Well-being of Young Offenders}

Social support from close persons for an incarcerated individual is of a particular importance [43]. The perception of available social support can alleviate the stress caused by imprisonment and have a positive impact on the individual after release [44,45]. Biggam and Power report that inmates perceiving a low level of support experience a higher level of anxiety [46]. Inmates perceiving a greater social support report a greater importance of family, friendship, social involvements, higher expectations and lower levels of recidivism [47]. Due to the lack of interaction with the representatives of "the primary group", or the lack of any support from them, social support from the representatives of "the secondary group" comes to the forefront. Other inmates, officers, psychologists and educators play an important role in young offenders' adjustment. In this regard, the study of the relationship of actions, acts and the staff's attitudes with the psychological well-being and emotional state of incarcerated youth is an important issue of the research. In the conditions of deprivation of liberty, the concepts of the legitimacy and fairness of actions and acts of the staff have a special meaning for the individual [48].

It is shown that under certain conditions, prisoners are more willing to accept staff's authority, and that staff's attitude to juvenile offenders has a greater impact on their emotional state than the conditions of detention and other factors [49].

Thus, the intuitive idea that any social support has a positive impact on the emotional state and on psychological well-being of the prisoner is far from being always confirmed in the results of research. The role of social support may depend on its type (perceived/received), the individual features of the recipient and the one who helps, the source of support (family, friends and strangers) and the circumstances of the situation.

\section{Purpose}

Our research aimed at the role of social support in the emotional well-being of young offenders. We hypothesized that perceived social support would be positively related to the emotional 
well-being of young offenders. Nevertheless, the role of the perceived social support would be mediated by other factors, such as the source of social support and the stage of criminal proceeding.

\section{Materials and Methods}

\subsection{Participants}

The entire sample consisted of 56 males aged 15 to 18 years old $(M=16.5$; $S D=0.8)$. Of this sample, 29 participants were ethnic Russians, and 27 were from other ethnic groups. 32 subjects $(57 \%)$ were in the pretrial detention and 24 participants $(43 \%)$ were in a correctional camp located in the central region of Russia. The participation in the research was completely voluntary.

According to the Russian law, during the investigation, prior to the announcement of the verdict of the court, the accused minors are in the pretrial detention. After the announcement of the verdict of the court, the convicts sentenced to imprisonment are transferred into correctional camps. There are 23 correctional camps in the Russian penal system. As of 2019, 982 minors are in the pretrial detention. Due to the humanization of the Russian criminal and penal legislation with regard to the measures applied to juvenile offenders, serving sentences in camps is now considered to be an extreme measure for minors. This is the reason behind the steady decline in the number of inmates in correctional camps. For instance, there were over 12000 minors in the camps in 2014. And as of January 1st, 2019, only 1310 persons were serving a sentence in the correctional camps [50]. Thus, for the most part, the crimes committed by convicted persons in the camps for juveniles relate to the category of violent crimes: robbery $(11,9 \%)$, the deliberate causing of heavy harm to health $(9.2 \%)$, murder $(8.9 \%)$ and sexual crimes $(12.5 \%)$. The age range of convicts serving sentences in the juvenile camps is as follows: $14-15$ years old $-3.8 \%, 16-17$ years old $-72.3 \%$ and $18-19$ years old 23.9\%. Most of them are sentenced to long-term imprisonment: 390 persons for a term of 3 to 5 years and 202 individuals for a term of 5 to 8 years. Among those serving sentences in the camps, $12.4 \%$ are orphans or children deprived of parental custody [50].

\subsection{Methods}

Perceived Social Support was measured by the Multidimensional Scale of Perceived Social Support (MSPSS) [51]. The MSPSS is a 12-item standardized instrument that uses a Likert-type scale response to assess the respondents' perceptions of social support from family, friends and significant others. The response options varied between 1 (very strongly disagree) and 7 (very strongly agree).

The frequency of turning for support to different categories was measured by the item that allowed clarifying whom and how often the respondents turned for support to. A list of categories of the social environment of the adolescents was offered, and they were asked: "Who and how often will you turn to or would you seek help in the case of emotional or psychological problems?" The categories were groups of close people (parents, close relatives, partners and friends) and groups of formal relationships with the respondents (doctor, psychologist, clergyman and chance acquaintances). The responses varied on a 4-point scale between 1 (never) and 4 (always).

Subjective well-being was measured by the Warwick-Edinburgh Mental Well-Being Scale (WEMWBS) [52]. The scale contains 14 items and has been validated for use in a wide variety of different languages and cultural contexts and in many different settings including the workplace, schools and health services. The WEMWBS covers subjective well-being and psychological functioning. Each item is worded positively and addresses an aspect of positive mental health.

The severity of positive and negative affect was measured by the Positive and Negative Affect Schedule (PANAS) [53]. We used the brief form that contains 20 items, with 10 items measuring a positive affect (e.g., excited, inspired, etc.) and 10 items measuring a negative affect (e.g., upset, afraid and so on). Each item is rated on a five-point Likert Scale ranging from 1 (very slightly or not at all) to 5 (extremely) to measure the extent to which the affect had been experienced in a specified time frame. We used the adapted version of the scale translated into Russian [54]. 
Feelings experienced by the respondents recently (the past 4 weeks) were assessed by The Scale of Positive and Negative Experience (SPANE) which includes six items for positive feelings and six items for negative feelings. Two subscales were combined to create the affect balance [55].

The negative emotional states such as depression, anxiety and stress were measured by The Depression Anxiety Stress Scales (DASS). The subjects were asked to use 4-point severity/frequency scales to rate the extent to which they had experienced each state to over the past week. The scores for Depression, Anxiety and Stress were calculated by summing the scores for the relevant items. The used brief form has 21 items with 7 items per scale [56].

\subsection{Statistical Methods}

All the statistics were calculated with SPSS 18.0 for Windows. We used the nonparametric Mann-Whitney U test, nonparametric Wilcoxon test and nonparametric correlation (Spearman's rho); a $p$ value $<0.05$ was considered to be significant.

\section{Results}

\subsection{Perceived Social Support}

Table 1. Mean values (M), standard deviation (SD), and the ranks of perceived social support in the correctional camp group and pretrial detention group on the subscale and on the general MSPSS scale.

\begin{tabular}{ccccccc}
\hline & \multicolumn{3}{c}{ Correctional camp } & \multicolumn{3}{c}{ Pretrial detention } \\
Subscales & \multicolumn{3}{c}{ group } & \multicolumn{3}{c}{ group } \\
& M & SD & Rank & M & SD & Rank \\
\hline Significant others & 5.34 & 1.62 & 3 & 4.89 & 1.99 & 3 \\
Family & 5.86 & 1.47 & 1 & 5.47 & 1.79 & 1 \\
Friends & 5.45 & 1.64 & 2 & 4.97 & 1.88 & 2 \\
General scale & 16.66 & 4.27 & & 15.34 & 5.16 & \\
\hline
\end{tabular}

Table 1 presents the results of certain subscales (significant others, family and friends) and on the general MSPSS scale. Among the sources of support, the respondents of both groups demonstrate the perception of family support to the greatest extent and statistically significantly (the Wilcoxon criterion, $p<0.05$ ). The average level of perceived social support in the adolescents of the camp from all the sources is higher than in the juveniles of the pretrial detention but the differences do not reach statistical significance (the Mann-Whitney U test).

\subsection{Subjective Assessment of the Frequency of Seeking Help from the Various Sources of Support}

Table 2. Mean values (M), standard deviation (SD) and the ranks of subjective estimates of the frequency of seeking help in the correctional camp group and pretrial detention group in the various sources of social support.

\begin{tabular}{ccccccc}
\hline $\begin{array}{c}\text { Source of social } \\
\text { support }\end{array}$ & \multicolumn{3}{c}{$\begin{array}{c}\text { Correctional camp } \\
\text { group }\end{array}$} & \multicolumn{3}{c}{$\begin{array}{c}\text { Pretrial detention } \\
\text { group }\end{array}$} \\
& M & SD & Rang & M & SD & Rang \\
\hline Parents & 3.17 & 0.82 & 1 & 2.77 & 0.92 & 1 \\
Close relatives & 2.70 & 0.97 & 3 & 2.55 & 0.93 & 3 \\
Teachers & 2.09 & 0.97 & 4 & 2.33 & 1.03 & 4 \\
Partners & 1.58 & 0.77 & 7 & 2.12 & 1.09 & 5 \\
Friends & 2.76 & 0.83 & 2 & 2.70 & 0.92 & 2 \\
Doctor & 1.40 & 0.60 & 8 & 1.52 & 0.79 & 8 \\
Psychologist & 1.81 & 0.81 & 5 & 1.73 & 0.94 & 6 \\
\hline
\end{tabular}




\begin{tabular}{ccccccc} 
Clergyman & 1.67 & 0.97 & 6 & 1.59 & 0.95 & 7 \\
Chance & 1.10 & 0.31 & 9 & 1.47 & 0.78 & 9 \\
acquaintances & & & & & & \\
\hline
\end{tabular}

Table 2 presents a subjective assessment of the frequency of seeking help from the various sources in the correctional camp group and pretrial detention group. The respondents from both groups indicate that they turn to their parents most often, then to friends and close relatives, and to doctors and chance acquaintances least often. Teachers and psychologists fall into the intermediate group. The comparison of the results of these groups by the two parameters of social support (perceived support and frequency of turning to various sources) using the Spearman's rank correlation coefficient reveals the following differences. The perception of support from the family and the frequency of seeking support from family members are directly correlated for the juveniles of the pretrial detention $(\mathrm{r}=0.442$ when $p=0.015$ - for the frequency of turning to parents and $\mathrm{r}=$ 0.468 when $p=.09$ - for close relatives); at the same time, the respondents of the camp do not find such associations. In addition, the responses of the adolescents from the pretrial detention are more consistent, which may indicate a less pronounced social desirability.

\subsection{Psychological Well-being}

Table 3. Mean values (M) and standard deviation (SD) of the level of psychological well-being (on the WEMWBS scale) in the correctional camp group and pretrial detention group.

\begin{tabular}{ccccc}
\hline Variable & \multicolumn{2}{c}{$\begin{array}{c}\text { Correctional } \\
\text { camp group }\end{array}$} & \multicolumn{2}{c}{$\begin{array}{c}\text { Pretrial } \\
\text { detention } \\
\text { group }\end{array}$} \\
& M & SD & M & SD \\
\hline $\begin{array}{c}\text { Psychological } \\
\text { well-being }\end{array}$ & 57.21 & 7.07 & 49.34 & 13.07 \\
\hline
\end{tabular}

Table 3 shows the results on the WEMWBS scale in the correctional camp group and pretrial detention group. The level of psychological well-being among the inmates of the camp is significantly higher in comparison with the respondents from the pretrial detention (the Mann-Whitney U-test: $U=220.5 p=0.007$ ). The level of psychological well-being of the respondents of the camp is not associated with any perceived social support (the Spearman's rank correlation coefficient), and the frequency of seeking assistance from the various sources of support (the Spearman's rank correlation coefficient). For the respondents of the pretrial detention, the level of psychological well-being is directly related to the degree of perceived support from friends (the Spearman's rank correlation coefficient: $\mathrm{r}=0.420$ when $p=0.019$ ).

\subsection{Positive and Negative Affects}

Table 4. Mean values (M) and standard deviation (SD) of the level of positive and negative affects (the PANAS method) in the Correctional camp group and pretrial detention group.

\begin{tabular}{ccccc}
\hline Variable & \multicolumn{2}{c}{$\begin{array}{c}\text { Correctional } \\
\text { camp group }\end{array}$} & \multicolumn{2}{c}{$\begin{array}{c}\text { Pretrial } \\
\text { detention } \\
\text { group }\end{array}$} \\
& M & SD & M & SD \\
\hline Positive affect & 30.32 & 5.79 & 31.44 & 7.52 \\
Negative affect & 18.18 & 8.69 & 21.37 & 7.39 \\
\hline
\end{tabular}

Table 4 shows the average values and standard deviations of positive and negative affect in two groups of the respondents on the PANAS scale. The intensity of the positive affect in both groups is significantly higher than that of negative affect (the Wilcoxon criterion: $\mathrm{W}=-4.930$ when $p<0.001$ ). The values of the positive affect do not differ significantly between the two groups, and the 
estimates of the negative affect differ at the trend level (the Mann-Whitney $\mathrm{U}$ test: $\mathrm{U}=214.5 p=$ 0.077): the adolescents from pretrial detention have more negative experiences than convicts in the camps. For the adolescents from the camp, the severity of the negative affect is directly related to the frequency of seeking help from close relatives (the Spearman's rank correlation coefficient: $r=0.481$ when $p=0.027$ ). For the respondents of the pretrial detention, the intensity of positive affect is directly related to the perceived social support from friends (the Spearman's rank correlation coefficient: $r=0,645$ when $p<0.001$ ) and the average level of perceived social support (the Spearman's rank correlation coefficient: $\mathrm{r}=0.484$ when $p=0.012$ ). It is inversely related to the frequency of seeking help from doctors (the Spearman's rank correlation coefficient: $r=-0.401$ when $p=0.042$ ) and clergymen (the Spearman's rank correlation coefficient: $\mathrm{r}=-0,414$ when $p=0.035$ ).

\subsection{Positive and Negative Feelings}

Table 5. Mean values (M) and standard deviations (SD) of the severity of negative feelings, positive feelings and the affect balance (SPAN) in the correctional camp group and pretrial detention group

\begin{tabular}{ccccc}
\hline Variable & \multicolumn{2}{c}{$\begin{array}{c}\text { Correctional } \\
\text { camp group }\end{array}$} & \multicolumn{2}{c}{$\begin{array}{c}\text { Pretrial } \\
\text { detention } \\
\text { group }\end{array}$} \\
& $\mathbf{M}$ & SD & M & SD \\
\hline Positive feelings & 21.4 & 4.43 & 18.35 & 5.14 \\
Negative feelings & 9.65 & 4.03 & 14.19 & 5.06 \\
Affect balance & 11.75 & 7.12 & 4.15 & 8.74 \\
\hline
\end{tabular}

Table 5 presents the results on the SPANE scale. The intensity of positive feelings in all the respondents is significantly higher than that of negative feelings (the Wilcoxon criterion: $\mathrm{W}=-4.466$ when $p<0.001$ ). When comparing the results of the two groups, it has turned out that the adolescents of the camp have significantly higher values of positive feelings (the Mann-Whitney $U$ test: $\mathrm{U}=162.5 p=0.030$ ) and the affect balance (the Mann-Whitney $\mathrm{U}$ test: $\mathrm{U}=124,5 p=0.003$ ) than the juveniles of pretrial detention. For the adolescents of the camp, positive feelings, negative feelings and the affect balance are associated neither with the perception of social support, nor with the frequency of seeking help from the various sources of support (the Spearman's rank correlation coefficient). For the adolescents from pretrial detention, positive feelings and the affect balance are directly connected to the degree of perceived support from significant close persons, friends and to the general perception of support (the Spearman's rank correlation coefficient: $r$ is from 0.425 to 0.641 when $p<0.05$ ); and the assessment of negative experience is inversely associated with the perceived support from the family (the Spearman's rank correlation coefficient: $\mathrm{r}=-0.422$ when $p=$ 0.036 ) and the frequency of turning to parents (the Spearman's rank correlation coefficient: $\mathrm{r}=-0.555$ when $p=0.003$ ), close relatives (the Spearman's rank correlation coefficient: $\mathrm{r}=-0.440$ when $p=$ 0.024 ) and teachers (the Spearman's rank correlation coefficient: $\mathrm{r}=-0.450$ when $p=0.021$ ).

Table 6. Mean values (M) and standard deviation (SD) of the severity of anxiety, depression and stress (according to the DASS method) in the correctional camp group and pretrial detention group

\begin{tabular}{ccccc}
\hline Variable & \multicolumn{2}{c}{$\begin{array}{c}\text { Correctional } \\
\text { camp group }\end{array}$} & \multicolumn{2}{c}{$\begin{array}{c}\text { Pretrial } \\
\text { detention } \\
\text { group }\end{array}$} \\
& M & SD & M & SD \\
\hline Depression & 5.50 & 7.51 & 8.52 & 7.50 \\
Anxiety & 4.67 & 6.23 & 8.39 & 7.58 \\
Stress & 6.75 & 7.10 & 11.10 & 8.58 \\
\hline
\end{tabular}

Table 6 shows the mean and standard deviations of anxiety, depression and stress on the DASS scale. When comparing the two groups on these indicators, it turns out that the level of anxiety is significantly higher in the adolescents of pretrial detention, (the Mann-Whitney $U$ test: $U=255.5 p=$ 
0.044 ), the severity of depression is higher at the trend level, (the Mann-Whitney $U$ test: $U=260.5 p=$ 0.055 ) as well as stress (the Mann-Whitney $\mathrm{U}$ test: $\mathrm{U}=260.5 \mathrm{p}=0.056$ ).

\section{Discussion and conclusions}

The results indicate that the level of psychological well-being is significantly higher in the juveniles serving a sentence in the correctional camp, and the emotional state and experienced feelings are significantly more positive than in the adolescents awaiting a court decision in the pretrial detention. In particular, the differences are identified at the level of psychological well-being on the whole and the level of depression, anxiety and stress. In addition, the adolescents from pretrial detention have stronger negative feelings and lower values of the balance between positive and negative feelings caused by the experience during the recent weeks.

A significantly higher level of psychological well-being of the respondents of the camps in comparison with the respondents in pretrial detention may be associated with substantially different conditions of detention and features of the social environment in the two types of the institutions. The important role of the detention conditions and the staff's attitudes in the psychological well-being of the juvenile prisoners is previously shown [49]. A distinctive feature of pretrial detention is the maximum isolation of a minor, living in the closed cells, the absence of long-term visits and no possibility to go beyond the institution. The accused individuals may be granted with no more than two visits per month from relatives and other persons for up to three hours. Although the conditions for self-education and exercising are provided, there is no systematic educational process. In the correctional camps, convicts are not actually limited in their movement through the territory of the correctional camp. The convicts are enrolled in the systematic educational process aimed at developing a law-obedient behaviour and honest attitude to work and study. They are engaged in the vocational training and additional vocational education. Convicts have permission for fairly frequent visits from relatives, both short-term and long-term. All convicts are entitled to communicate with family and friends by telephone and video, if technically possible. In order to provide systematic psychological assistance to minors, correction and preparation for release, psychological laboratories have been established in each camp [22].

In addition to the differences in the conditions of detention and in the environment of two groups of the respondents, the features of perceived social support at the different stages of the criminal trial impact the psychological well-being and emotional state of the juveniles. Generally speaking, the psychological well-being and emotional state of the respondents of the pretrial detention only is associated with the perceived social support from the different sources, while such connections are not identified almost for the adolescents in the camp. Social support from the family comes to the forefront in the perception of the respondents, despite the fact that the vast majority of the adolescents serving sentences have not earlier in their lives had any healthy social environment. Moreover, their social connections formed within deviant groups, often in the families of criminals or alcoholics [57]. At the same time, the results of the study indicate that the perceived social support from parents and other family members is not related to the level of their psychological well-being and emotional state. In the case of the juveniles in the pretrial detention, the psychological well-being and emotional state is primarily associated with the perceived support from the friends and family but not parents. And in the case of the adolescents from the correctional camps, social support is virtually unrelated to psychological well-being and emotional state.

Thus, one may suppose that under the conditions of the educational environment organized in the camps for minors (when the redevelopment of their behaviour and system of values is carried out), the skills of a positive interaction with the staff, psychologists, educators and teachers are acquired, the opportunity to earn and pay for the satisfaction of their needs is presented. The dependence of the psychological well-being of juvenile offenders on the support of the people outside the new environment decreases.

More than a tenth of those in the correctional camps are orphans, and a greater part of them are "social orphans" - who have parents unable to create a favourable environment for the personal development of the child. This is a dysfunctional family that often acts as a criminogenic factor 
contributing to the illegal behaviour of a minor [58]. According to Vygotsky, the reasons for the "moral insanity" of a minor "should not be found in the child, but out of him or her - in the socioeconomic and cultural-pedagogical conditions in which the child grew and developed. In other conditions favourable to the child's development and in another environment, a difficult child loses the features of moral insanity very quickly and takes a new path". [59] (p. 150). Breaking connections with the criminal environment, an unhealthy environment and growing autonomy and independence can contribute to the successful re-education of the teenager who committed a crime, and his re-socialization after release.

Author Contributions: Conceptualization, F.U., R.S., L.S. and Y.Z.; Methodology, R.S., L.S., A.D. and O.V.; Software, O.A. and O.V.; Formal Analysis, L.S. and A.D.; Investigation, F.U., R.S., L.S., A.D.; Resources, F.U., L.S. and A.D.; Data Curation, A.D. and O.V.; Writing-Original Draft Preparation, L.S., A.D., O.A. and O.V.; Writing-Review \& Editing, F.U., R.S., Y.Z.; Visualization, O.V.; Supervision, R.S., L.S. and Y.Z.; Project Administration, A.D. and O.V.; Funding Acquisition, R.S. and L.S.

Funding: This research was funded by Russian Foundation for Basic Research grant number 17-29-02506.

Conflicts of Interest: The authors declare no conflict of interest. The funders had no role in the design of the study; in the collection, analyses, or interpretation of data; in the writing of the manuscript, and in the decision to publish the results.

Availability of Data and Materials: The datasets used and analyzed during the current study are available from the corresponding author on reasonable request.

\section{Abbreviations}

DASS Depression Anxiety Stress Scales

MSPSS Multidimensional Scale of Perceived Social Support

PANAS Positive and Negative Affect Schedule

SPANE Scale of Positive and Negative Experience

WEMWBS Warwick-Edinburg Mental Well-Being Scale

\section{References}

1. Alsubaie, M.M.; Stain, H.J.; Webster, L.A.D.; Wadman, R. The role of sources of social support on depression and quality of life for university students. International Journal of Adolescence and Youth 2019, pp. 1-13. DOI: $10.1080 / 02673843.2019 .1568887$

2. Liu, T.-H.; De Li, S.; Zhang, X.; Xia, Y. The Spillover Mechanisms Linking Family Conflicts and Juvenile Delinquency Among Chinese Adolescents. International Journal of Offender Therapy and Comparative Criminology 2019, pp. 1-20. DOI: 10.1177/0306624X19842057

3. Adolescent mental health, Available online: https://www.who.int/news-room/fact-sheets/detail/adolescent-mental-health (accessed on 11 may 2019).

4. Mulder, E.; Brand, E.; Bullens, R.; van Marle, H. Toward a Classification of Juvenile Offenders: Subgroups of Serious Juvenile Offenders and Severity of Recidivism. International Journal of Offender Therapy and Comparative Criminology 2019, 63, pp. 819-836. DOI: 10.1177/0306624X10387518

5. van der Put, C.E.; van Vugt, E.S.; Stams, G.J.J.M.; Deković, M.; van der Laan, P.H. Short-Term General Recidivism Risk of Juvenile Sex Offenders: Validation of the Washington State Juvenile Court Prescreen Assessment. International Journal of Offender Therapy and Comparative Criminology 2013, 57, pp. 1374-1392. DOI: $10.1177 / 0306624 \times 12457775$

6. Waite, D.; Keller, A.; McGarvey, E.L.; Wieckowski, E.; Pinkerton, R.; Brown, G.L. Juvenile sex offender re-arrest rates for sexual, violent nonsexual and property crimes: A 10-year follow-up. Sexual Abuse 2005, 17, pp. 313-331. DOI: 10.1177/107906320501700305

7. Forrester-Jones, R. Reflections on a Young Offenders Institution: Communication-A Need, a Want, a Right. International Journal of Offender Therapy and Comparative Criminology 2006, 50, pp. 218-231. DOI:10.1177/0306624X05279040

8. McCann, K.; Lussier, P. Antisociality, sexual deviance, and sexual reoffending in juvenile sex offenders. A meta-analytical investigation. Youth Violence and Juvenile Justice 2008, 6, pp. 363-385. 
9. Villanueva, L.; Gomis-Pomares, A.; Adrián, J.E. Predictive Validity of the YLS/CMI in a Sample of Spanish Young Offenders of Arab Descent. International Journal of Offender Therapy and Comparative Criminology 2019, pp. 1-17. DOI: 10.1177/0306624X19834403

10. Kholmogorova, A.B.; Smirnova, N.S. Complex model of interpersonal relationships as a theoretical basis for their study in adolescents with behavioral disorders. Cultural-historical psychology, Russia, 2009, 4, pp. 94-99.

11. Andrews, F.M.; Withey, S.B. Social Indicators of Well-Being. Plenum Press: New York, 1976.

12. Diener, E. Subjective well-being. Psychological Bulletin 1984, 95, pp. 542-575.

13. Liang J. A structural integration of the Affect Balance Scale and the Life Satisfaction Index. Journal of Gerontology 1985, 40, pp. 552-561.

14. Ryan, R.M.; Deci, E.L. To be happy or to be self-fulfilled: A review of research on hedonic and eudemonic well-being. Annual Review of Psychology 2001, 52, pp. 141-166.

15. Bradburn, N.M. The Structure of Psychological Well-Being. Chicago: Aldine Publishing Co., 1969.

16. Vygotsky, L.S. The Problem of Age. Vygotsky L.S. Collected Works: In 6 v. Russia, 1983; Volume 4, pp. 244-268.

17. Elkonin, D.B. On the problem of the periodization of mental development in childhood. Questions of psychology, Russia, 1971, 4, pp. 6-20.

18. Podolsky, A.I.; Karabanova, O.A.; Idobaeva, O.A.; Kheymans, P. The psycho-emotional well-being of modern adolescents: the international research experience. The Moscow University Bulletin. Series 14. Psychology, Russia, 2011, 2, pp. 9-20.

19. Poskrebysheva, N.N.; Karabanova, O.A. The study of the personal autonomy of a teenager in the context of the social situation of development. National Psychological Journal, Russia, 2014, 16, pp. 34-41.

20. Lehmann, P.S.; Chiricos, T.; Bales, W.D. Juveniles on Trial: Mode of Conviction and the Adult Court Sentencing of Transferred Juveniles. Crime $\mathcal{E}$ Delinquency 2018,64, pp. 563-586. DOI:10.1177/0011128717714203

21. Singer, S.I. Sentencing Juveniles to Life in Prison: The Reproduction of Juvenile Justice for Young Adolescents Charged with Murder. Crime \& Delinquency 2011, 57, pp. 969-986. DOI: 10.1177/0011128710396426

22. Ushkov, F.I. Psychological characteristics of interpersonal contacts between psychologists FSIN of Russia and convicted minors. Statements of the penitentiary system, Russia, 2017, 7, pp. 22-26.

23. Uchino, B.N. Social support and health: A review of physiological processes potentially underlying links to disease outcomes. Journal of Behavioral Medicine, 2006, 29, pp. 377-387. DOI: 10.1007/s10865-006-9056-5

24. Rigby, K. Effects of peer victimization in schools and perceived social support on adolescent well-being. Journal of Adolescence 2000, 23, pp. 57-68. DOI: 10.1006/jado.1999.0289

25. Chen, Y.; Feeley, T.H. Social support, social strain, loneliness, and well-being among older adults: An analysis of the Health and Retirement Study. Journal of Social and Personal Relationships 2014, 31, pp. 141-161. DOI: 10.1177/0265407513488728

26. Walen, H.R.; Lachman, M.E. Social support and strain from partner, family, and friends: Costs and benefits for men and women in adulthood. Journal of Social and Personal Relationships 2000, 17, pp. 5-30. DOI: 10.1177/0265407500171001

27. Muñoz-Laboy, M.; Severson, N.; Perry, A.; Guilamo-Ramos, V. Differential impact of types of social support in the mental health of formerly Incarcerated Latino men. American Journal of Men's Health 2014, 8 , pp. 226-239. DOI: 10.1177/1557988313508303

28. Moak, Z.B.; Agrawal, A. The association between perceived interpersonal social support and physical and mental health: results from the national epidemiological survey on alcohol and related conditions. Journal of Public Health 2010, 32, pp. 191-201. DOI: 10.1093/pubmed/fdp093

29. Cohen, S.; Wills, T.A. Stress social support, and the buffering hypothesis. Psychological Bulletin 1985, 98, pp. 310-357.

30. Cummins, R.C. Perceptions of social support, receipt of supportive behaviors, and locus of control as moderators of the effects of chronic stress. American Journal of Community Psychology 1988, 16, pp. 685-700.

31. Cullen, F.T.; Wright, J.P.; Chamlin, M.B. Social support and social reform: A progressive crime control agenda. Crime \& Delinquency 1999, 2, pp. 188-207.

32. Barrera, M. Distinctions between social support concepts, measures, and models. American Journal of Community Psychology 1986, 14, pp. 413-445. 
33. Vangelisti, A.L. Challenges in conceptualizing social support. Journal of Social and Personal Relationships 2009, 26, pp. 39-51. DOI: 10.1177/0265407509105520

34. Haber, M.G.; Cohen, J.L.; Lucas, T.; Baltes, B.B. The relationship between self-reported received and perceived social support: A meta-analytic review. American Journal of Community Psychology 2007, 39, pp. 133-144. DOI: 10.1007/s10464-007-9100-9

35. Lakey, B.; Adams, K.; Neely, L.; Rhodes, G.; Lutz, C.J.; Sielky, K. Perceived support and low emotional distress: The role of enacted support, dyad similarity, and provider personality. Personality and Social Psychology Bulletin 2002, 28, pp. 1546-1555. DOI: 10.1177/014616702237582

36. Eagle, D.E.; Hybels, C.F.; Proeschold-Bell, R.J. Perceived social support, received social support, and depression among clergy. Journal of Social and Personal Relationships 2019,36, pp. 2055-2073. DOI: 10.1177/0265407518776134

37. Myroniuk, T.W.; Anglewicz, P. Does social participation predict better health? A longitudinal study in rural Malawi. Journal of Health and Social Behavior 2015, 56, pp. 552-573. DOI: 10.1177/0022146515613416

38. Reinhardt, J.P.; Boerner, K.; Horowitz, A. Good to have but not to use: Differential impact of perceived and received support on well-being. Journal of Social and Personal Relationships 2006, 23, pp. 117-129. DOI: 10.1177/0265407506060182

39. Billings, A.G.; Moos, R.H. The Role of Coping Resources in Attenuating the Stress of Life Events. Journal of Behavioral Medicine, 1981, 4, pp. 139-157. DOI: 10.1007/BF00844267

40. Lively, K.J.; Heise, D.R. Emotions in affect control theory. In Handbook of the Sociology of Emotions; J. Stets \& J. Turner, Eds.; Dordrecht: Springer, 2014, Volume 2, pp. 51-75.

41. Pierce, K.D.; Quiroz, C.S. Who matters most? Social support, social strain, and emotions. Journal of Social and Personal Relationships 2018. DOI: 10.1177/0265407518817400

42. Thoits, P.A. Mechanisms Linking Social Ties and Support tj Physical and Mental Health. Journal of Health and Social Behavior, 2011, 52(2), pp. 145-161. DOI: 10.1177/0022146510395592

43. Colvin, M. Applying differential coercion and social support theory to prison organizations: The case of the Penitentiary of New Mexico. The Prison Journal 2007, 87, pp. 367-387. DOI: 10.1177/0032885507304774

44. Listwan, S.J.; Colvin, M.; Hanley, D.; Flannery, D. Victimization, Social Support, and Psychological Well-Being: A Study of Recently Released Prisoners. Criminal Justice and Behavior 2010, 37, pp. 1140-1159. DOI: $10.1177 / 0093854810376338$

45. Valera, P.; Boyas, J.F. Perceived Social Ties and Mental Health Among Formerly Incarcerated Men in New York City. International Journal of Offender Therapy and Comparative Criminology 2019, pp. 1-18, DOI: 10.1177/0306624X19832239

46. Biggam, F.H.; Power, K.G. Social support and psychological distress in a group of incarcerated young offenders. International Journal of Offender Therapy and Comparative Criminology 1997 41, pp. 213-230. DOI: 10.1177/0306624X97413002

47. Paterline, B.A.; Petersen, D.M. Structural and social psychological determinants of prisonization. Journal of Criminal Justice 1999, 5, pp. 427-441.

48. Sparks, J.R.; Bottoms, A.E. Legitimacy and order in prisons. British Journal of Sociology 1995, 46, pp. 45-62. DOI: $10.2307 / 591622$

49. Cesaroni, C.; Peterson-Badali, M. The Role of Fairness in the Adjustment of Adolescent Boys to Pretrial Detention. The Prison Journal 2016, 96, pp. 534-553. DOI: 10.1177/0032885516650877

50. Federal Penitentiary Service of Russia. Available online: http://fsin.su/ (accessed on 11 th May, 2019).

51. Zimet, G.D.; Dahlem, N.W.; Zimet, S.G.; Farley, G.K. The multidimensional scale of perceived social support. Journal of Personality Assessment 1988, 52, pp. 30-41. DOI: 10.1207/s15327752jpa5201_2

52. Tennant, R.; Hiller, L.; $\quad$ Fishwick, R.; $\quad$ Platt, S.; Joseph, S.; Weich, S.; Parkinson, J.; Secker, S.; Stewart-Brown, S. The Warwick-Edinburgh Mental Well-being Scale (WEMWBS): development and UK validation. Health $\mathcal{E}$ Quality of Life Outcomes 2007, 63, pp. 1-13. DOI: 10.1186/1477-7525-5-63

53. Watson, D.; Clark, L.A.; Tellegen, A. Development and validation of brief measures of positive and negative affect: The PANAS scales. Journal of Personality and Social Psychology 1988, 54, pp. 1063-1070.

54. Osin, E.N. The measurement of positive and negative emotions: development of the Russian-language analogue of the PANAS technique. Psychology. Journal of Higher School of Economics, Russia, 2012, 9, pp. 91-110.

55. Diener, E.; Wirtz, D.; Tov, W.; Kim-Prieto, C.; Choi, D.; Oishi, S.; Biswas-Diener, R. New measures of well-being: Flourishing and positive and negative feelings. Social Indicators Research 2009, 39, pp. 247-266. 
56. Lovibond, P.F.; Lovibond, S.H. The structure of negative emotional states: Comparison of the Depression Anxiety Stress Scales (DASS) with the Beck Depression and Anxiety Inventories. Behaviour Research and Therapy 1995, 33, pp. 335-343.

57. Kuznetsova, I.A. Characteristics of the personality of juvenile convicts serving a sentence of imprisonment. NovaInfo.Ru, Russia, 2016, 41. Available online: https://novainfo.ru/article/4635 (accessed on 11th May 2019).

58. Pestrikov, D.V.; Senik, I.V. Psychological features and measures of prevention of the suicidal behavior of convicts serving the sentence of imprisonment. NovaInfo.Ru 2015, 31. Available online: https://novainfo.ru/article/3203 (accessed on 11 may 2019).

59. Vygotsky, L.S. Moral insanity. Vygotsky L.S. Collected Works: In 6 v. Russia, 1983; Volume 5, pp. $150-152$. 